Asy-Syar'iyyah: Jurnal Ilmu Syari'ah dan Perbankan Islam - ISSN 2089-7227 (p)

Vol. 2, No. 1 (2017), pp. 80 - 101

\title{
UPAYA PREVENTIF BERKEMBANGNYA MONEY GAME DI INDONESIA
}

\author{
Harizan \\ STAIN Syaikh Abdurrahman Siddik Bangka Belitung
}

\begin{abstract}
Based on the fact lately, there were some methods of seeking treasure in social life nowadays. One of them was Money Game (the term of Money Game actually never found in any encyclopedia neither Wikipedia, but found only for interpretation of Ponzi Scheme Business), through members' or investors' recruitment. They were promised getting profit from their membership and investment, more than any bank even conventional or sharia banking ever promised. The last case of Money Game method was Dream for Freedom (D4F), found in year 2015 and ended in April 2016. The founder offered the extra ordinary profit and benefit, such as 1\% profit per a day from member's investment. This condition successfully recruited hundred thousands of members, from the low rank of education to the high one. Indonesian's Government such as the Financial Services Authority (OJK) actually has been preventing the people from being victims and spreading of Money Game's methods, but still the founder of any Money Game find the way to eliminate those preventing ways. Therefore Government has to try another way, through involving another institutional, even government's Institutional or Social's Institutional and organizations.
\end{abstract}

Keywords : Money Game, the Financial Services Authority (OJK), Ponzi Scheme 


\section{Pendahuluan}

Beberapa tahun terakhir, Money Game sangat marak terjadi di Indonesia. Baik disaat kondisi perekonomian sedang baik, maupun disaat kondisi ekonomi tidak stabil. Hal ini disebabkan oleh impian untuk mendapatkan uang dengan mudah, tanpa harus bersusah payah bekerja keras.

Istilah Money Game sesungguhnya tidak dikenal di dalam ensiklopedi asing, yang penulis coba telusuri. Definisi Money Game dijelaskan oleh Majelis Ulama Indonesia melalui fatwa Dewan Syari'ah Nasional (DSN) No 75/DSNMUI/VII/2009 Tentang Pedoman Penjualan Langsung Berjenjang Syari'ah (PLBS), pada ketetapan pertama ayat 9 yang menjelaskan bahwa Money Game adalah kegiatan penghimpunan dana masyarakat atau penggandaan uang dengan praktik memberikan komisi dan bonus dari hasil perekrutan/pendaftaran Mitra Usaha yang baru/bergabung kemudian dan bukan dari hasil penjualan produk, atau dari hasil penjualan produk namun produk yang dijual tersebut hanya sebagai kamuflase atau tidak mempunyai mutu/kualitas yang dapat dipertanggung jawabkan.

Pada bulan Agustus $2014^{1}$ Otoritas Jasa keuangan (OJK) mengidentifikasikan ada 750 perusahaan investasi penipuan, akhirnya OJK merilis daftar 262 nama perusahaan ilegal tersebut. Kebanyakan diantara perusahaan tersebut melakukan aksinya dengan modus MLM, investasi valas, investasi emas, sampai perkebunan dan peternakan. Bahkan ada juga usaha yang menggunakan kedok agama untuk memuluskan aksinyamenghimpun dana dari masyarakat. Dari jumlah tersebut, 218 merupakan penawaran investasi tanpa izin dari pihak berwenang, sementara 44 sisanya terkait dengan kewenangan sejumlah instansi seperti Kementerian Koperasi dan Usaha Mikro, Kecil Menengah, Badan Pengawas Perdagangan Komoditi Berjangka, Kementerian Perindustrian dan Perdagangan, serta Kementerian

${ }^{1}$ https://howmoneyindonesia.com/2014/11/07/ojk-ini-dia-daftar-262-perusahaaninvestasibisnis-bodong/ 
Hukum dan Hak Asasi Manusia. Meskipun demikian, modusnya hampir sama yaitu Money Game piramida atau ponzi.

Sampai dengan 11 Juni 2016 seperti yang dilansir oleh http:/ / finance.detik.com, masyarakat telah menyampaikan adanya permintaan informasi dan/atau pertanyaan terhadap legalitas 430 perusahaan yang menawarkan investasi kepada masyarakat. Dari sejumlah itu terdapat 374 tawaran investasi yang berkajtan dengan keuangan (antara lain emas. forex. emoney. e-commerce. investasi haji dan umroh) sementara sisanya sebanyak 56 tawaran berupa investasi di bidang properti. tanaman. komoditas dan perkebunan. Setelah dilakukan penelitian lebih lanjut. seluruh perusahaan yang menawarkan investasi dan diragukan aspek legalitasnya tersebut, ternyata tidak satupun yang terdaftar di OJK. Dari jumlah tersebut. terdapat 388 tawaran dari perusahaan yang belum diketahui kejelasan izin beroperasi, 13 tawaran dari perusahaan yang memiliki SIUP/TDP tetapi tidak memiliki izin yang terkait dengan investasi yang dilakukan.

Menyikapi maraknya pertumbuhan dan perkembangan moneygame, sudah sewajarnya pemerintah melalui lembaga yang memiliki kewenangan untuk mengatur perekonomian, perbankan, perdagangan dan keuangan untuk memberikan perhatian khusus, sehingga tidak banyak lagi korban-korban pemimpi yang terjebak dalam impian kaya dalam waktu singkat, tanpa menjalani usaha nyata.

\section{Identifikasi Masalah}

Money Game atau Penggandaan uang atau permainan uang, secara sederhana dapat diartikan sebagai cara berbisnis yang tidak wajar dan cenderung menipu yang dilakukan oleh perusahaan investasi palsu, dengan cara menawarkan produk investasi yang dijamin pasti aman dan pasti untung. Produk investasi yang ditawarkan dapat berupa kerjasama bisnis pertanian dan perkebunan, kerjasama perdagangan pulsa telepon, kerjasama bisnis 
peternakan burung onta, perdagangan emas, tabungan haji, kerjasama investasi di pasar modal dan lain-lain².

Money Game identik dengan Ponzi Scheme, yaitu sebuah metode pengumpulan investasi yang dilakukan oleh Charles Ponzi. Charlez Ponzi,adalah imigran asal Italia. Pertama kali melakukan penipuan dengan cara menggelapkan uang yang dikirimkan oleh imigran Italia ke Negara asal mereka. Korban pertamanya adalah temannya sendiri. Pada waktu itu, Ponzi meminjam uang 20 dollar AS dengan janji akan mengembalikan keuntungan $50 \%$. Ponzi kemudian meminjam uang lagi dari teman lainnya dan mengembalikan uang tersebut ke teman yang pertama. Berkaca dari pengalaman tersebut, Charles Ponzi akhirnya membentuk perusahaan bernama Securities Exchange Company dan menawarkan bagi hasil sebesar 50\% dari setiap investasi yang ditanamkan. Untuk meyakinkan para investor, Charles Ponzi menyatakan dia menginvestasikan dana tersebut untuk membeli kupon pos internasional dan mengonversikan nilainya dengan dollar AS. Modus penipuan semacam ini lazim pula dinamakan money game atau penggandaan uang $^{3}$. Seusai perang dunia I dia berhasil menghimpun dana 9,5 juta US Dollar dari sekitar 100.000 investor dalam waktu yang singkat, dengan metode yang dikenal dengan Skema Ponzi. Menurut Wikipedia Skema Ponzi adalah modus investasi palsu yang membayarkan keuntungan kepada investor dari uang mereka sendiri atau uang yang dibayarkan oleh investor berikutnya, bukan dari keuntungan yang diperoleh oleh individu atau organisasi yang menjalankan operasi ini ${ }^{4}$.

Frank L Brunetti menyatakan : "A Ponzi scheme can be described as a fraudulent investment operation that pays returns to its investors, from their own

\footnotetext{
${ }^{2}$ Serfianto, dkk, Multi Level Marketing, Money Game \& Skema Piramid, (Jakarta, PT Elex Media Computindo, 2011), hal. 69.

${ }^{3}$ Ibid, hal. 81

${ }^{4}$ https://id.wikipedia.org/w/index.php?search=money+game\&title= diakses pada tanggal 28 November 2016.
} 
money or the money paid by subsequent investors, rather than from profit earned by the individual or organi-zation running the operation. The Ponzi scheme usually entices new investors by offering higher returns than other invest- ments"

Skema Ponzi bisa dikenali biasanya membujuk investor baru dengan menawarkan pengembalian keuntungan kepada para penanam modal yang sesungguhnya berasal dari uang mereka sendiri atau dari uang yang dibayarkan oleh penanam modal dibawahnya, bukan berasal dari keuntungan yang didapat dari bisnis yang dioperasikan, Skema Ponzi biasanya selalu mencoba mengajak investor baru dengan penawaran keuntungan yang tinggi dibandingkan investasi yang lain. ${ }^{5}$.

Money Game atau Skema Piramid merupakan sistem bisnis ilegal, dimana keuntungan yang diperoleh sejumlah orang yang berada pada posisi atas piramid (anggota lama) dibayarkan dari dana sejumlah orang yang berada pada posisi bawah piramid (anggota baru). Praktek bisnis dengan konsep Money Game atau Skema Piramid di Indonesia berasal dari Skema Ponzi yang pertama kali diterapkan Jusup Handojo Ongkowidjaja dalam Yayasan Keluarga Adil Makmur (YKAM) yang didirikannya pada tahun 1987 di Jakarta. ${ }^{6}$ Ongko memperkenalkan YKAM sebagai usaha tabung-pinjam gotong royong yang menawarkan paket kredit sebesar Rp 5 juta tanpa bersusah payah dalam pengurusan administrasinya. Syaratnya peserta cukup membayar biaya pendaftaran sebesar Rp 50.000, dan menyetor tabungan Rp 30.000 sebanyak tujuh kali dalam waktu satu bulan. Pengembalian pinjaman Rp 5 juta tersebut dapat diangsur selama 15 tahun dan jika sudah lunas, peminjam juga dijanjikan bonus sebesar Rp 9,6 juta. Pada akhir februari 1988 member yang bergabung di YKAM mencapai lebih dari 44.000 orang dengan paket terdaftar sebanyak 70.000 buah, yang tersebar di lebih dari 20 kota se Indonesia.

${ }^{5}$ Frank L Brunetti, Defining Ponzi-Scheme Losses (New Jersey Law Journal, Vol 208. No 10, June 11, 2012)

${ }^{6} \mathrm{http}: / /$ repository.unib.ac.id/1280/ 
Selanjutnya, arisan berantai Danasonic. Ada 500.000 peserta dan dana yang terkumpul Rp 110 miliar. Tahun 2002, Ramly Arabi, unsur pimpinan PT Qurnia Subur Alam Raya, divonis penjara 8 tahun dan denda Rp 10 miliar karena kasus penggandaan uang. Kasus lain, agen penjualan produk investasi Dressel Investment Limited. Penjualan tanpa izin Badan Pengawas Pasar Modal dan Lembaga Keuangan (Bapepam-LK) itu menggaet 10.000 nasabah dan uang $\operatorname{Rp} 3,5$ triliun?.

Di Medan tahun 1996, Money Game sempat berjaya lewat PT Banyumas Mulia Abadi (BMA). Konsep yang dipakai BMA waktu itu penjualan produk jeans namun yang menjadi nilai jual (selling point) adalah pengembalian modal hingga 1,5-2 kali lipat dari modal awal. Contoh, jika seseorang 'nasabah' belanja 1 paket jeans senilai Rp 1,5 juta maka 21 hari kemudian menjadi sebesar Rp 2,5 juta sehingga orang tertarik bukan pada paket produknya melainkan pada janji bonusnya. BMA akhirnya bubar karena pengelolanya kabur setelah menggondol uang nasabah miliaran rupiah. Setelah itu muncul Money Game yang sama bak cendawan di musim hujan sekitar tahun 1996-1999. Ada PT. Permata Nusantara, New Era 21, CKSS (Citra Keluarga Sejahtera Sentosa), PT. MLM (Mekar Langsung Mandiri), PT. MLM (Media Laksana Mandiri), PT. IJP (Inter Jasa Perkasa), BMM (Bisnis Masyarakat Medan), PT. Rosindo, dan Higam Net (Hidup Gembira Awet Muda Network). Perusahaan-perusahaan ini akhirnya juga bubar karena pengelola kabur setelah menghimpun dana masyarakat yang sangat banyak ${ }^{8}$.

Menurut Serfianto Skema piramid atau jaringan Multi Level Marketing (MLM) terlarang memiliki cara kerja yang berbeda dengan Money Game. Skema piramid dapat dianggap sebagai jaringan penjualan berjenjang (multi level marketing) yang terlarang atau MLM palsu. Sedangkan Money Game umumnya

\footnotetext{
${ }^{7}$ http://megapolitan.kompas.com/amp/read/2012/01/06/05273928/OJK.agar.Jangan.Jatuh.Korb an.Baru

${ }^{8} \mathrm{http}$ //harian.analisadaily.com/opini/news/ojk-tak-berdaya-money-gameberjaya/126822/2015/04/22
} 
dipraktekkan oleh perusahaan yang berkedok penjualan langsung satu jenjang 9 (direct selling/single marketing). Pada kenyataannya saat ini skema piramid digunakan oleh system Money Game, baik yang berkedok investasi, arisan, komunitas, online dan sebagainya.

Sistem Skema Piramida adalah sebagai berikut ${ }^{10}$ :

1. Mitra usaha dianjurkan untuk mendaftar berkali-kali atau beberapa kavling sekaligus agar memperoleh keuntungan yang lebih besar.

2. Tidak ada barang atau jasa sebagai produknya. Kalaupun ada, hanya digunakan sebagai kedok dan harganya tidak sebanding dengan mutu dan kualitasnya.

3. Mengutamakan rekrut anggota sebagai pendapatan utama, bukan dari penjualan produk.

4. Tidak ada pelatihan khusus bagi mitra usaha.

5. Tidak adanya buy back guarantee, karena barang atau jasa memang dianggap tidak penting.

6. Tidak memiliki Surat Izin Usaha Penjualan Langsung (SIUPL) Sesuai dengan Peraturan Menteri Perdagangan RI Nomor 13/M $\neg$ DAG/PER/3/2006 Tentang Ketentuan Dan Tata Cara Penerbitan Surat Izin Usaha Penjualan Langsung

Craig Cantoni menjelaskan bahwa skema pyramid meskipun terkait erat dengan skema ponzi, tetap bisa ditemukan perbedaan diantara keduanya, " $A$ Ponzi Scheme is closely related to a Pyramid because it revolves around continuous recruiting, but in a ponzi scheme the promoter generally has no product to sell and pays no commission to investors who recruit new members. Instead. The promoter collects

\footnotetext{
${ }^{9}$ Serfianto, dkk, Multi Level..., hal. 71.

${ }^{10}$ http://repository.unair.ac.id/11578/, diakses pada tanggal 28 November 2016.
} 
payments from a stream people, promising them all the same high rate of return on a short term investment"11.

Banyak perusahaan investasi, arisan atau perusahaan berkedok MLM dengan skema pyramid yang mencari keuntungan dengan cara memutarkan uang anggotanya dengan menggunakan Money Game. Cara ini beresiko bukan hanya ada pada anggota, tetapi juga pada perusahaan. Anggota perusahaan Money Game seperti ini mudah sekali berkembang. Dalam hitungan bulan saja sudah ribuan orang bergabung, karena iming-iming keuntungan yang menggiurkan. Para anggota yang sudah bergabung ini semacam dihipnotis oleh senior mereka atau orang suruhan perusahaan. Mereka dijanjikan keuntungan yang berlipat. Mereka juga didoktrin dengan berbagai macam presentasi yang menyilaukan (kompasiana.com).

Otoritas jasa Keuangan (OJK) dan Satuan Tugas Penanganan Dugaan Tindakan Melawan Hukum di Bidang Penghimpunan Dana Masyarakat dan Pengelolaan Investasi (Satgas Waspada Investasi) mencatat, ada tiga perusahaan, yaitu PT Cakrabuana Sukses Indonesia (CSI), PT Dream for Freedom, dan UN Swissindo melakukan kegiatan melanggar hukum. Ketiganya dinyatakan sebagai perusahaan investasi yang tidak memiliki izin dari OJK. 12

Salah satu Money Game yang terakhir dilaporkan oleh membernya adalah Dream for Freedom (D4F). Jumlah member D4F saat pemilik (owner) nya dilaporkan berjumlah sekitar 700.000 anggota, dengan total kerugian member diperkirakan sebesar 3 Trilyun rupiah ${ }^{13}$. PT CSI mendirikan koperasi simpan pinjam dan pembiayaan syariah (KSPPS) dengan menghimpun dana dari masyarakat melalui investasi emas dan tabungan dengan imbal hasil 5\% per

${ }^{11}$ Craig J Cantoni, A Brief History of Ponzi Scheme, (Journal of American Physician and Surgeons, Vol 14, Number 1, Spring 2009)

12 https://finance.detik.com/moneter/d-3334243/3-perusahaan-investasi-bodong-ini-himpunuang-rp-35-triliun, diakses pada tanggal 28 November 2016

${ }^{13}$ Harizan, Dream for Freedom, Perspektif Hukum Islam, Penelitian Individu, (STAIN Syaikh Abdurrahman Siddik Bangka Belitung, 2015) 
bulan. Sedangkan, Dream for Freedom menawarkan produk investasi dengan menawarkan keuntungan 1\% selama 15 hari dan bonus aktif 10\% jika peserta dapat mengajak anggota baru.

Sementara berdasarkan penelitian yang dilakukan oleh Harizan, dari 100 responden, kerugian mencapai 1.370.387.003 (Satu Milyar Tiga Ratus Tujuh Puluh Juta Tiga Ratus Delapan Puluh Tujuh Ribu Tiga Rupiah) ${ }^{14}$. Korban yang tertipu tidak hanya dari masyarakat awam yang berpendidikan rendah, tapi juga masyarakat yang berpendidikan tinggi. Korban tidak juga berasal dari kalangan dari kelas ekonomi menengah ke bawah, tapi juga dari kelas ekonomi menengah ke atas. Hal ini menunjukkan, bahwa impian untuk kaya harta dengan cara pintas menjadi trend pemikat, sehingga sampai kapan pun impian ini tidak akan berhenti, jika tidak ada usaha prefentif dari pihak-pihak yang memiliki akses kebijakan dan hubungan langsung dengan masyarakat.

Bisnis ini sekilas terlihat sebagai bisnis yang sangat mudah dijalankan serta menjanjikan keuntungan besar. Jauh lebih besar dari pendapatan investasi normal sehingga sangat menarik terutama mereka yang merindukan keuntungan cepat. Biasanya dijalankan dengan meminta calon member (kadang disebut juga: downline, nasabah, investor) untuk terlibat dalam suatu bisnis, jumlah modal bisa bervariasi. Mereka cukup menyetor sejumlah uang, lalu mencari calon member lainnya untuk melakukan hal yang sama. Umumnya, untuk terlibat dalam bisnis ini para member cukup menyetor uang dan tidak ada produk yang diperjualbelikan. Terkadang ada produk yang dijual, tetapi sebenarnya merupakan produk kamuflase dalam rangka pengaburan bisnis utama nya yaitu Money Game.

Kasus-kasus penipuan jenis Money Game dan skema pyramid sudah sangat banyak terjadi dan selalu berulang kembali, dengan jumlah kerugian korban hingga triliunan rupiah. Fakta-fakta ini semestinya sudah dapat

14 Harizan, Dream for Freedom Pasca Restart dan Implikasinya pada Member. Penelitian Individu, (STAIN Syaikh Abdurrahman Siddik Bangka Belitung, 2016) 
dijadikan alassan bagi pemerintah dan Dewan Perwakilan Rakyat untuk segera menerbitkan Undang-undang Anti Money Game secara khusus ${ }^{15}$. Padahal secara legal formal, sudah ada beberapa peraturan perundang-undangan yang memiliki kesamaan klausul, yang dapat dijadikan dasar membuat Undangundang Anti Money Game.

\section{Pendekatan Legal Formal}

Berikut ini adalah beberapa pendekatan legal formal sebagai pertimbangan yang dapat dijadikan dasar penguat untuk segera di rumuskannya Undang-undang Anti Money Game di Indonesia.

1. Hukum Islam tentang Haramnya Money Game

a. Fatwa Dewan Syari' ah Nasional Majelis Ulama Indonesia (DSN-MUI No 75/DSN-MUI/VII/2009/Tentang Pedoman Penjualan Langsung Berjenjang Syari'ah (PLBS).

Tabel 1

\begin{tabular}{|l|l|l|l|}
\hline \multicolumn{3}{|c|}{ Pertimbangan Perbandingan Pasal PLBS \& Money Game } \\
\hline No & $\begin{array}{l}\text { Mengingat :3.b } \\
\text { "Ujrah/kompensasi sesuai dengan } \\
\text { tingkat kesulitan (Kerja)” }\end{array}$ & Ada & Tidak Ada \\
\hline 2 & $\begin{array}{l}\text { Keputusan pertama (ayat 2): } \\
\text { Barang adalah setiap benda berwujud, } \\
\text { baik bergerak maupun tidak bergerak, } \\
\text { dapat dihabiskan maupun tidak dapat } \\
\text { dihabiskan, yang dapat dimiliki, } \\
\text { diperdagangkan, dipakai, } \\
\text { dipergunakan, atau dimanfaatkan } \\
\text { oleh konsumen. }\end{array}$ & Ada & Tidak ada \\
\hline
\end{tabular}

${ }^{15}$ Serfianto, dkk, Multi Level ..., hal. 84 


\begin{tabular}{|c|c|c|c|}
\hline 3 & $\begin{array}{l}\text { Keputusan pertama (ayat 3): } \\
\text { Produk jasa adalah setiap layanan } \\
\text { yang berbentuk pekerjaan atau } \\
\text { pelayanan untuk dimanfaatkan oleh } \\
\text { konsumen. }\end{array}$ & Ada & Tidak ada \\
\hline 4 & $\begin{array}{l}\text { Keputusan Pertama (ayat 6): dan } \\
\text { Keputusan kedua (ayat 5) } \\
\text { Komisi adalah imbalan yang diberikan } \\
\text { oleh perusahaan kepada mitra usaha } \\
\text { atas penjualan, yang besaran } \\
\text { maupun bentuknya diperhitungkan } \\
\text { berdasarkan prestasi kerja nyata yang } \\
\text { terkait langsung dengan volume atau } \\
\text { nilai hasil penjualan barang dan atau } \\
\text { produk jasa. }\end{array}$ & Ada & Tidak Ada \\
\hline 5 & $\begin{array}{l}\text { Keputusan pertama (ayat 7): dan } \\
\text { keputusan kedua (ayat 6) } \\
\text { Bonus adalah tambahan imbalan yang } \\
\text { diberikan oleh perusahaan kepada mitra } \\
\text { usaha atas penjualan, karena berhasil } \\
\text { melampaui target penjualan barang dan } \\
\text { atau produk jasa yang ditetapkan } \\
\text { perusahaan }\end{array}$ & Ada & Tidak Ada \\
\hline 6 & $\begin{array}{l}\text { Keputusan Pertama (ayat 8): } \\
\text { Ighra' adalah daya tarik luar biasa yang } \\
\text { menyebabkan orang lalai terhadap } \\
\text { kewajibannya demi melakukan hal- hal atau } \\
\text { transaksi dalam rangka mempereroleh } \\
\text { bonus atau komisi yang dijanjikan }\end{array}$ & Ada & Ada \\
\hline 7 & $\begin{array}{l}\text { Keputusan pertama (ayat 9): } \\
\text { Money Game adalah kegiatan } \\
\text { penghimpunan dana masyarakat atau } \\
\text { penggandaan uang dengan praktik } \\
\text { memberikan komisi dan bonus dari hasil } \\
\text { perek- rutan/pendaftaran Mitra Usaha } \\
\text { yang baru/bergabung kemudian dan }\end{array}$ & $\begin{array}{c}\text { Tidak } \\
\text { ada }\end{array}$ & $\begin{array}{l}\text { Ada } \\
\text { Dan } \\
\text { memenuhi } \\
\text { unsur yang } \\
\text { dijelaskan } \\
\text { dalam ayat }\end{array}$ \\
\hline
\end{tabular}




\begin{tabular}{|c|c|c|c|}
\hline & $\begin{array}{l}\text { bukan dari hasil penjualan produk, } \\
\text { atau dari hasil penjualan produk } \\
\text { namun produk yang dijual tersebut } \\
\text { hanya sebagai kamuflase atau tidak } \\
\text { mempunyai mutu/kualitas yang dapat } \\
\text { dipertanggung jawabkan. }\end{array}$ & & ini. \\
\hline 8 & $\begin{array}{l}\text { Keputusan kedua (ayat } 1) \text { : } \\
\text { Ada obyek transaksi riil yang } \\
\text { diperjualbelikan berupa barang atau produk } \\
\text { jasa }\end{array}$ & Ada & Tidak Ada \\
\hline 9 & $\begin{array}{l}\text { Keputusan kedua (ayat 2): } \\
\text { Barang atau produk jasa yang } \\
\text { diperdagangkan bukan sesuatu yang } \\
\text { diharamkan dan atau yang dipergunakan } \\
\text { untuk sesuatu yang haram }\end{array}$ & Ya & $\begin{array}{c}\text { Tidak ada } \\
\text { produk } \\
\text { barang } \\
\text { maupun jasa, } \\
\text { Yang } \\
\text { dijadikan } \\
\text { objek akad } \\
\text { adalah uang } \\
\text { (barang } \\
\text { ribawi) }\end{array}$ \\
\hline 10 & $\begin{array}{l}\text { Keputusan kedua (ayat 3): } \\
\text { Transaksi dalam perdagangan tersebut } \\
\text { tidak mengandung unsur gharar, maysir, } \\
\text { riba, dharar, dzulm, maksiat }\end{array}$ & $\begin{array}{c}\text { Tidak } \\
\text { ada }\end{array}$ & $\begin{array}{l}\text { Ada, } \\
\text { mengandung } \\
\text { Gharar, } \\
\text { Maysir, Riba, } \\
\text { dharar dan } \\
\text { dzulm }\end{array}$ \\
\hline 11 & $\begin{array}{l}\text { Keputusan kedua (ayat 7): } \\
\text { Tidak boleh ada komisi atau bonus secara } \\
\text { pasif yang diperoleh secara reguler tanpa } \\
\text { melakukan pembinaan dan atau penjualan } \\
\text { barang dan atau jasa }\end{array}$ & $\begin{array}{c}\text { Tidak } \\
\text { ada }\end{array}$ & $A d a$ \\
\hline 12 & $\begin{array}{l}\text { Keputusan kedua (ayat 12): } \\
\text { Tidak melakukan kegiatan Money Game }\end{array}$ & Tidak & $\mathrm{Ya}$ \\
\hline
\end{tabular}


b. Keputusan Fatwa Musyawarah Komisi Fatwa MUI Kota Bandung Nomor: 291/MUI-KB/E.1/VII Tentang HUKUM BISNIS NETWORK MARKETING / MLM

Tabel 2

\begin{tabular}{|c|c|c|c|}
\hline \multicolumn{4}{|c|}{ Pertimbangan Pasal MLM \& Money Game } \\
\hline No & Pasal konsideran & MLM & Money Game \\
\hline 1 & $\begin{array}{l}\text { Mengingat 1.B bagian a: } \\
\text { MLM yang tidak menjual } \\
\text { produk, biasa disebut Money } \\
\text { Game (permainan uang). Contoh: } \\
\text { Pihak MLM menawarkan sebuah } \\
\text { sepeda motor merk } x \text { hanya } \\
\text { dengan menyetor uang Rp. } \\
2.000 .000 \text { dengan syarat harus } \\
\text { bisa menjaring sebanyak sepuluh } \\
\text { orang yang masing-masing harus } \\
\text { menyetorkan uang sebesar Rp. } \\
\text { 2.000.000 pula. la akan menerima } \\
\text { sepeda motor tersebut setelah } \\
\text { mampu menjaring sepuluh orang, } \\
\text { dan bila tidak, maka uang } \\
\text { tersebut hangus. Demikian } \\
\text { seterusnya. }\end{array}$ & $\begin{array}{c}\text { Bisa ada } \\
\text { bisa tidak }\end{array}$ & $\begin{array}{c}\text { Tidak menjual } \\
\text { produk sebagai } \\
\text { Pengganti Bonus } \\
\text { ('Iwadh) Sesuai } \\
\text { qaidah } \\
\text { Resiko menyertai } \\
\text { manfaat }\end{array}$ \\
\hline 2 & $\begin{array}{l}\text { Mengingat } 3 \text {. Point 3: } \\
\text { 'Adamu al-gharar (tidak } \\
\text { berspekulasi yang tidak jelas / } \\
\text { tidak transparan), }\end{array}$ & $\begin{array}{c}\text { Bisa ada, } \\
\text { Bisa tidak }\end{array}$ & $\begin{array}{c}\text { Dipastikan Ada } \\
\text { sebagaimana } \\
\text { pertimbangan pada } \\
\text { penjelasan } \\
\text { pembahasan }\end{array}$ \\
\hline 3 & $\begin{array}{l}\text { Mengingat 3. Poin 5: } \\
\text { 'Adamu Riba (tidak ada sistem } \\
\text { bunga-berbunga) }\end{array}$ & $\begin{array}{l}\text { Bisa ada, } \\
\text { bisa tidak }\end{array}$ & Ada \\
\hline 4 & $\begin{array}{l}\text { Mengingat 3. Poin 8: } \\
\text { Ta 'awun 'ala al-birr wa al- } \\
\text { taqwa (tolong menolong dalam }\end{array}$ & $\begin{array}{c}\text { Bisa ada } \\
\text { bisa tidak }\end{array}$ & $\begin{array}{l}\text { Niat tolong } \\
\text { menolong, tapi pada } \\
\text { praktek nya dalam }\end{array}$ \\
\hline
\end{tabular}




\begin{tabular}{|c|c|c|c|}
\hline & kebaikan dan taqwa), & & Itsmi wa al-'udwaani \\
\hline 5 & $\begin{array}{l}\text { Menimbang 6.C: } \\
\text { ضرر ولا ضرار. } \\
\text { "Tidak memudaratkan dan tidak } \\
\text { dimudaratkan (tidak saling } \\
\text { memudaratakan). " }\end{array}$ & $\begin{array}{c}\text { Bisa ada } \\
\text { bisa tidak }\end{array}$ & $\begin{array}{l}\text { Ada kemudharatan: } \\
\text { 1. Riba } \\
\text { 2. Gharar } \\
\text { 3. Menghasilkan } \\
\text { Harta Haram }\end{array}$ \\
\hline 6 & $\begin{array}{l}\text { Menetapkan, pertama: } \\
\text { MLM yang pertama yaitu MLM } \\
\text { yang tidak menjual produk } \\
\text { disebut Money Game (permainan } \\
\text { uang) hukumnya haram, karena } \\
\text { berupa penipuan yang nyata. }\end{array}$ & Tidak & $\mathrm{Ya}$ \\
\hline
\end{tabular}

2. Hukum Positif

a. (KUHP Bab XXV Pasal 378 Beserta Penjelasannya) ${ }^{16}$

Tindak pidana penipuan merupakan salah satu tindak pidana atau kejahatan terhadap harta benda. Dalam arti yang luas tindak pidana ini sering disebut bedrog. Di dalam KUHP, bedrog diatur dalam bab XXV pasal 378 sampai dengan 395. Dalam rentang pasalpasal tersebut, bedrog kemudian berubah menjadi bentuk-bentuk penipuan yang lebih khusus.Bentuk-Bentuk Penipuan, Unsur, dan Akibat Hukumnya.

Money Game menurut hemat penulis termasuk dalam penipuan pokok yang diatur dalam pasal 378 KUHP yang berbunyi: "Penipuan adalah barang siapa dengan maksud menguntungkan diri sendiri atau orang lain dengan melawan hukum, baik menggunakan nama palsu atau keadaan palsu, maupun dengan tipu daya, ataupun dengan rangkaian perkataan-perkataan bohong,

${ }^{16}$ http://hukumpidana.bphn.go.id/babbuku/bab-xxv-perbuatan-curang/ 
membujuk orang supaya menyerahkan barang atau supaya membuat utang atau menghapus piutang.

Dari pernyataan di atas dapat disimpulkan bahwa dalam penipuan tidak menggunakan paksaan akan tetapi dengan tipu muslihat seseorang untuk mempengaruhi orang lain sehingga orang tersebut bertindak tanpa kesadaran penuh.

Unsur-unsur penipuan pokok tersebut dapat dirumuskan:

a. Unsur-unsur Objektif

1) Perbuatan: menggerakkan atau membujuk;

2) Yang digerakkan: orang

3) Perbuatan tersebut bertujuan agar:

a) Orang lain menyerahkan suatu benda;

b) Orang lain memberi hutang; dan

c) Orang lain menghapuskan piutang.

4) Menggerakkan tersebut dengan memakai:

a) Nama palsu;

b) Tipu muslihat,

c) Martabat palsu; dan

d) Rangkaian kebohongan.

b. Unsur-unsur Subjektif

1) Dengan maksud (met het oogmerk);

2) Untuk menguntungkan diri sendiri atau orang lain;

3) Dengan melawan hukum.

\section{Temuan dan Diskusi}

1. Merancang dan Mensahkan Undang-undang / Peraturan Tindak pidana Money Game

Ada beberapa temuan ide yang penting untuk dipertimbangkan untuk mengantisipasi berkembangnya Money Game di Indonesia, antara 
lain adalah Merancang dan mensahkan Undang-undang atau peraturan tindak pidana Money Game. Hal ini menjadi sangat penting untuk diperhatikan bila belum ada payung hukum yang bisa mempidanakan pelaku Money Game. Hal ini bisa terjadi jika Otoritas hukum Indonesia menyadari bahwa pelindungan terhadap warga negara terhadap kejahatan kerah putih (white collar crime) dalam bentuk (Money Game/skema ponzi/sistem piramida). Mengingat besarnya potensi kerugian yang dialami masyrakat oleh aktifitas Money Game, maka dengan adanya peraturan yang mengenai Money Game akan menghindari hal-hal berikut ${ }^{17}$;

a. Membatasi ruang gerak para penggiat Money Game, yang biasanya akan berpindah dari satu bentuk Money Game ke Money Game yang lain dengan istilah mengunci (lock) posisi diatas sehingga terhindar dari kerugian, dikarenakan posisinya diatas puncak rantai makanan.

b. Membatasi ruang gerak mafia Money Game yang berinvestasi hanya untuk meraih keuntungan dari member di bawahnya (downline).

c. Menghindari pencucian uang yang bisa saja di manfaatkan dengan adanya Money Game ini.

d. Membatasi keserakahan masyarakat dalam mendapatkan harta dengan cepat, yang diakibatkan janji keuntungan besar diluar batas kewajaran, bahkan perbankan sebagai lembaga keuangan tidak berani menjanjikannya.

Peraturan ini juga bisa menjadi landasan untuk:

a. Memberikan hukum yang jelas dan berat terhadap inisiator sebuah Money Game yang terbukti bersalah baik owner, Manager maupun pemodal.

${ }^{17}$ https://www.facebook.com/groups/241310076202892 
b. Memberi panduan jelas terhadap aktifitas Bisnis Online yang reliable, dengan Bisnis Online yang tidak jelas dan tidak memiliki izin usaha nyata.

c. Menjadi pembeda antara investasi yang benar seperti tabungan, saham dan sebagainya dengan Money Game, investasi bodong, arisan berantai dan penipuan dengan cara mengumpulkan dana masyarakat ${ }^{18}$.

\section{Satuan Tugas (Satgas) Khusus Money Game}

Otoritas Jasa Keuangan (OJK) saat ini memiliki satuan tugas khusus yang mengawasi investasi, yang disebut satgas waspada investasi (http://waspadainvestasi.ojk.go.id), sebagai Satuan Tugas Penanganan Dugaan Tindakan Melawan Hukum di Bidang Penghimpunan Dana Masyarakat dan Pengelolaan Investasi yang dibentuk berdasarkan Keputusan Dewan Komisioner Otoritas Jasa Keuangan Nomor : 01/KDK.01/2016 tanggal 1 Januari 2016.

Satgas Waspada Investasi merupakan wadah koordinasi antar regulator, instansi pengawas, instansi penegak hukum dan pihak lain yang terkait dalam hal penanganan dugaan tindakan melawan hukum di bidang penghimpunan dana masyarakat dan pengelolaan investasi. Satgas Waspada Investasi dibentuk melalui Surat Keputusan Ketua Bapepam dan LK Nomor: Kep-208/BL/2007 tanggal 20 Juni 2007 untuk masa kerja tahun 2007 yang diperbarui setiap tahunnya ${ }^{19}$.

Meskipun sudah memiliki satuan tugas khusus yang mengawasi investasi, namun ternyata Satgas yang dibawah naungan OJK ini, masih

${ }^{18}$ Ide dan usulan diatas berasal dari masyarakat yang peduli terhadap masyarakat yang dikhawatirkan menjadi korban bujukan Money Game yang berkedok Multi Level Marketing, bisnis online ataupun investasi. Meski terkadang mereka dikucilkan, dicemooh dan dianggap sebagai orang yang iri terhadap kesuksesan orang lain.

${ }^{19} \mathrm{http}: / /$ waspadainvestasi.ojk.go.id 
belum melaksanakan fungsi nya dengan maksimal, hal ini terbukti dengan banyak nya investasi bodong yang mengakibatkan banyak korban dari masyarakat hingga milyaran rupiah. Sehingga kebutuhan akan satuan tugas khusus tambahan mutlak diperlukan, sehingga dapat mencegah terjadinya korban yang diakibatkan oleh Money Game.

\section{Edukasi Masyarakat tentang Money Game}

Revitalisasi pelaksanaan tugas satgas waspada investasi yaitu sosialisi kepada komponen masyarakat, penegak hukum, pemerintah daerah dan akademisi ${ }^{20}$. Pembentukan satgas untuk tiap daerah menjadi sebuah kewajiban yang tidak bisa dihindari, untuk mempermudah akses pemantauan, pelaporan dari masyarakat dan penindakan secara cepat, serta pembinaan masyarakat. Edukasi masyarakat hingga saat ini masih kurang dan belum menyentuh seluruh lapisan masyarakat, sehingga format edukasi diharapkan lebih elegan dan sistematis, dengan melibatkan komponen masyarakat yang berhubungan langsung. Pembentukan satgas pendamping satgas waspada investigasi layak untuk dipertimbangkan, seperti kelompok, asosiasi dan atau organisasi masyarakat.

4. Memberdayakan Media Sosial sebagai Perpanjangan tangan Satgas Waspada Investasi

Berdasarkan pengamatan penulis, di media sosial sudah banyak grup, kelompok atau komunitas yang melakukan tugas satgas waspada investasi sebagai pengawas dan pengamat model investasi atau pun bisnis yang "mengarah" atau disinyalir berujung pada Money Game atau skema ponzi, antara lain grup ; 
a. Dream for Freedom Watch (D4F WATCH) ${ }^{21}$

Grup yang memberikan edukasi secara proporsional dan professional tentang bisnis D4F yang berkembang pesat pada tahun 2015, dan akhirnya collapse pada tahun 2016, dengan meninggalkan banyak korban dari masyarakat yang dana nya tidak dikembalikan. ${ }^{22}$

b. Koperasi Bintang Abadi Sejahtera Watch (KOBAS WATCH) ${ }^{23}$

c. MSS Melia Sehat Sejahtera Watch24

d. Moment Watch 25

e. Khoir Community Watch ${ }^{26}$

Terlepas apakah nantinya yang diawasi dan diamati, benar-benar masuk dalam kategori bisnis Money Game, ponzi atau tidak, namun paling tidak, gerakan yang dilakukan menunjukkan bahwa penggunaan media sosial sebagai sarana untuk mengawasi terjadinya investasi bodong atau Money Game cukup efektif untuk memberikan edukasi bagi mereka yang sedang di ajak seseorang untuk bergabung dalam bisnis.

\section{Kesimpulan}

Menimbang banyaknya kerugian baik secara materiil mau pun moril yang ditimbulkan oleh Money Game, maka Pemerintah melalui lembaga terkait harus segera:

1. Merumuskan dan mensahkan Undang-undang Anti Money Game, sehingga bisa dilakukan usaha preventif yang bisa menekan perkembangan bisnis Haram ini.

${ }^{21}$ https://www.facebook.com/groups/604419402993973/?ref=ts\&fref=ts

${ }^{22}$ Untuk pembahasan tentang Dream for Freedom Perspektif Hukum Islam dan Dream for Freedom Pasca Restart dan Implikasinya pada Member, sudah diteliti dan belum di publikasikan.

${ }^{23} \mathrm{https}: / / \mathrm{www}$.facebook.com/groups/727680570718659/?ref=ts\&fref=ts

${ }^{24} \mathrm{https} / / / \mathrm{www}$. facebook.com/groups/MSS.Watch/?ref=ts\&fref=ts

${ }^{25} \mathrm{https}: / / \mathrm{www}$. facebook.com/groups/watcherofmoment/?ref=ts\&fref=ts

${ }^{26} \mathrm{https}: / / \mathrm{www}$. facebook.com/groups/1564631730342109/?ref=ts\&fref=ts 
2. Menindak tegas Pelaku Money Game, baik Pemilik (Owner), Founder (Pendiri) dan Manager (Peringkat Jabatan tertentu), dengan menggunakan klausul Hukum baik Pidana mau pun Perdata yang relevan. Agar bisa memberikan efek jera bagi pemain Money Game

3. OJK atau Lembaga yang memiliki kewenangan hendaknya membuat Satgas Khusus Pemantau Money Game, yang berfungsi praktis langsung ke masyarakat sekaligus berperan sebagai tenaga edukasi. 


\section{DAFTAR PUSTAKA}

Frank L Brunetti, Defining Ponzi-Scheme Losses (New Jersey Law Journal, Vol 208. No 10, June 11, 2012)

Craig J Cantoni, A Brief History of Ponzi Scheme, (Journal of American Physician and Surgeons, Vol 14, Number 1 , Spring 2009)

Harizan, Dream for Freedom, Perspektif Hukum Islam, Penelitian Individu, (STAIN Syaikh Abdurrahman Siddik Bangka Belitung, 2015)

Harizan, Dream for Freedom Pasca Restart dan Implikasinya pada Member.

Penelitian Individu, (STAIN Syaikh Abdurrahman Siddik Bangka Belitung, 2016)

Serfianto, dkk, Multi Level Marketing, Money Game E Skema Piramid, (Jakarta, PT Elex Media Computindo, 2011)

https://www.facebook.com/groups/241310076202892

https://www.facebook.com/groups /604419402993973/?ref=ts\&fref=ts

https://www.facebook.com/groups/727680570718659/?ref=ts\&fref=ts

https://www.facebook.com/groups/MSS.Watch/?ref=ts\&fref=ts

https://www.facebook.com/groups/watcherofmoment/?ref=ts\&fref=ts

https://www.facebook.com/groups/1564631730342109/?ref=ts\&fref=ts

http:/ / finance.detik.com/bursa-valas/3238738/awasi-investasi-bodong-ojkgandeng-6-kementerian-lembaga

https:/ / finance.detik.com/moneter/d-3334243/3-perusahaan-investasibodong-ini-himpun-uang-rp-35-triliun

http://harian.analisadaily.com/opini/news/ojk-tak-berdaya-money-gameberjaya/126822/2015/04/22

http://hukumpidana.bphn.go.id/babbuku/bab-xxv-perbuatan-curang/

https:/ /howmoneyindonesia.com/2014/11/07/ojk-ini-dia-daftar-262perusahaan-investasibisnis-bodong/

https://id.wikipedia.org/w/index.php?search=money+game\&title= 
http:/ / megapolitan.kompas.com/amp/read/2012/01/06/05273928/OJK.agar. Jangan.Jatuh.Korban.Baru

http:/ / repository.unair.ac.id/11578/,

http:/ / repository.unib.ac.id/1280/

http:/ / waspadainvestasi.ojk.go.id 